\title{
Syngas Production and Losses Encountered in Gasification of Rice Husks
}

\author{
Ethel D. Kasembe1, Zacharia M. Mganilwa'1, Geoffrey R. John², Cuthbert F. Mhilu² \\ ${ }^{1}$ Department of Transport and Engineering Technology, National Institute of Transport, Dar es Salaam, \\ Tanzania \\ ${ }^{2}$ College of Engineering and Technology, University of Dar es Salaam, Dar es Salaam, Tanzania \\ Email: ekasembe@gmail.com
}

Received December 2014

\section{Abstract}

This paper addresses the syngas production and evaluation losses in high temperature gasification process using coffee husks. A fast and inexpensive way to evaluate the losses in gasification processes is by the application mathematical models which allow to predict the values needed in full scale. Hence, the quantification of gasifier's losses at temperatures ranges of $800 \mathrm{~K}-1400 \mathrm{~K}$ at an equivalence ratios of $0.3,0.35$ and 0.4 at 1 bar are revealed by using exergy model incorporating a chemical equilibrium model. The model evaluated the product syngas compositions, syngas heating values and degree of irreversibility values (losses). The results from the model showed that the production of $\mathrm{H} 2$ increased from $9.9 \%$ to $18.9 \%$ and the formation of $\mathrm{CO}_{2}$ ranges from $7.2 \%$ to $12.3 \%$. CO production is from $21.8 \%$ to $17.2 \%$. The irreversibility values obtained were less than $\mathbf{2 7 \%}$. Hence, reduction of losses protracts biomass resources to be used in energy generation.

\section{Keywords}

Coffee Husks, Equivalence Ratio, Exergy, Gasification, Irreversibility (Losses)

\section{Introduction}

\subsection{Biomass as a Primary Energy Source}

There are worries that a widespread use of gasifiers could greatly increase the pressure in existing wood and charcoal supplies, and in areas of fuel scarcity, particularly for those who depend mainly on biomass fuels could be severe. But these can be contained by the advent of second generation biofuels which introduces the use of residues that are left on the field or those resulting from biomass treatment plants. The valorisation of the agricultural residues and by-products through their use as second generation feedstock may give the opportunity for decreased pressure in the use of crop and forestry products for the generation of fuel from biomass. Biomass materials with high energy potential include agricultural residues such as straws, bagasses, coffee husks and rice husks as well as residues from forest-related activities such as wood chips, sawdust and bark. As an example, the estimated biomass potentials for energy generation for Tanzania in 2005 was an annual agricultural waste includes corn stalks and cobs (7.7 million tons), rice husk and straw (4.1 million tons), bagasse (447,030 tons), 
wheat straw (232,000 tons), sisal fibres (46,000 tons) and cashew nut shells (30,100 tons) providing a total sum of wastes generated of about 12.6 million tons while the world production of biomass is estimated at 146 billion metric tons a year, mostly wild plant growth [1].

However, the level of utilization of biomass depends on economics and availability of the necessary technology. Use of biomass as a fuel poses some challenges due to its inherent low calorific value as the hygroscopic nature of biomass which leads to a high moisture content, even after drying cause a negative effect on the efficiency of thermal processing equipment. As such, a sustainable management, conversion, and delivery of biomass as a form of modern and affordable energy resource is in need. To achieve the above the application of a novel conversion technology of biomass is desirable.

\subsection{Gasification Process}

Gasification process is believed to be a highly efficient technology for converting biomass materials into useful gas energy source, since, first, it can offer a greater reduction potential on the formation of $\mathrm{CO}_{2}$ and NOx compounds when compared to conventional combustion technologies. Secondly, thermo gasification products can offer a relatively higher equipment efficiency when used in electricity generation compared to direct com- bustion application for the same [2] [3]. The values of gasification efficiency vary from $80 \%$ to $85 \%$ as reported by [4] while [5] shows that the values of efficiency for electricity generation from biomass combustion range from $15 \%$ to $35 \%$. The gasification process can take place at low (around $700^{\circ} \mathrm{C}-750^{\circ} \mathrm{C}$ ) or high temperatures (above $750^{\circ} \mathrm{C}$ ). At high temperature the syngas is free from tars as large part of it is cracked into gaseous products [6].

\subsection{Exergy Analysis}

In order to improve the system process efficiency, there is a need to optimize its process because a thermodynamic improvement in a particular point such as in pyrolysis may have negative repercussions in other sections such as reduction or oxidation in the case of gasifiers. The quantification of irreversibilities is done by the application of the effectiveness of process deploying availability concept which is based on the second law of thermodynamics [7] [8]. The exergy concept was introduced to overcome limitations of the energy analysis and is the maximum ability of the system to perform work relative to human environment. Analysis of exergy losses provides information as to where the real inefficiencies in a system lie so as to detect and evaluate quantitatively the losses that occur in thermal and chemical processes. The identification of the inefficiencies and their sources allows having an effective management and optimization of thermal systems [9].

Poor thermodynamic performance is the result of exergy losses in thermal processes [10]. The majority of the causes of thermodynamic imperfection of thermal and chemical processes can be detected by analyzing the process performance using exergy analysis as opposed to energy or enthalpy balances. Normally, the exergy contained in the biomass material is converted into chemical exergy of the product gas, physical exergy; the rest is the unavailable energy due to process irreversibilities.

Thermomechanical exergy, or physical exergy, is the maximum amount of work that can be achieved by a state of a substance as it comes into thermal and mechanical equilibrium with the environment. Neglecting kinetic and potential energy contributions in the analysis, processes are considered to be at steady flow state, the molar specific physical exergy of a species at temperature $\mathrm{T}$ and pressure $\mathrm{p}$ is defined by:

$$
\varepsilon_{p h}=\left(h-h_{o}\right)-T_{o} \cdot\left(s-s_{o}\right)
$$

where $h$ and s are the molar specific enthalpy and molar specific entropy, and the subscript "o" denotes the state of the environment.

Chemical exergy on the other hand is the maximum work potential of a substance at the dead state as it comes into chemical equilibrium with the environment [11]. Because it is evaluated at the dead state, chemical exergy does not have a thermal component to it, thus differentiating it from physical exergy. The chemical exergy of a gas stream of multiple components can be computed by summation of their partial chemical exergies by [12] as:

$$
\varepsilon_{c h}=\sum_{i} \chi_{i} \varepsilon_{c h, i}+R_{o} T_{o} \sum_{i} \chi_{i} \ln \chi_{i}
$$

where $\chi_{i}$ and $\varepsilon_{c h, i}$ are the mole fraction and chemical exergy of individual gas component $i$ respectively, Ro is the universal gas constant and $T_{o}$ is the standard temperature. 


\section{Methodology}

\subsection{Selecting a Template Material Characteristics Analysis}

Representative sample of biomass that underwent proximate analysis, and parameters obtained, adopted methods contained in standard test procedures for determining the individual parameters. The moisture content (MC) is determined using the ASTM E-949 standard, volatile matter (MV) by ASTM E-872 and ash content (Ash) by ASTM E-1755-95. The fixed carbon is determined as the difference from $100 \%$ of the sum of the $\left(\mathrm{MC} \%+\mathrm{VM} \%+\right.$ Ash \%). The Vecslar furnace, Model LF 3 with a maximum offsetting temperature of $1100^{\circ} \mathrm{C}$ is used to determine the parameters. The procedure included the determination of weight by weighing samples in a Mettler AE 240 Dual Range balance.

The biomass sample elemental composition including $C, H$ and $O$ from the proximate analysis experiments are then correlated in accordance to the method of [13] given by:

$$
\begin{aligned}
C & =0.637 F C+0.455 V M \\
H & =0.052 F C+0.062 V M \\
O & =0.304 F C+0.476 V M
\end{aligned}
$$

where $F C, V M, C, H$ and $O$ are percentage mass of fixed carbon, volatile matter, carbon, hydrogen and oxygen on a dry basis.

\subsection{Composition of Syngas Components}

The biomass involved in the gasification is represented by a general formula $\mathrm{CH}_{\mathrm{x}} \mathrm{O}_{\mathrm{y}} \mathrm{N}_{z}$ and the gasification equation is represented "6" as:

$$
\begin{aligned}
& \mathrm{CH}_{x} \mathrm{O}_{y} \mathrm{~N}_{z}+a \mathrm{H}_{2} \mathrm{O}+b\left(\mathrm{O}_{2}+3.76 \mathrm{~N}_{2}\right) \\
& \rightarrow n_{\mathrm{H}_{2}} \mathrm{H}_{2}+n_{\mathrm{CO}} \mathrm{CO}+n_{\mathrm{CO}_{2}} \mathrm{CO}_{2}+n_{\mathrm{H}_{2} \mathrm{O}} \mathrm{H}_{2} \mathrm{O}+n_{\mathrm{CH}_{4}} \mathrm{CH}_{4}+(\mathrm{z} / 2+3.76 \mathrm{~m}) \mathrm{N}_{2}
\end{aligned}
$$

The application of the first law of thermodynamics using the thermochemical equilibrium modeling via the mole balance and equilibrium constants relations of atoms in the reactants to those in the products is necessary and results in the following equations emanating from the global gasification reaction " 6 ":

Carbon balance:

$$
f_{1}=0=n_{\mathrm{CO}}+n_{\mathrm{CO}_{2}}+n_{\mathrm{CH}_{4}}-1
$$

Hydrogen balance:

$$
f_{2}=0=2 n_{\mathrm{H}_{2}}+2 n_{\mathrm{H}_{2} \mathrm{O}}+4 n_{\mathrm{CH}_{4}}-x-2 w
$$

Oxygen balance:

$$
f_{3}=0=n_{\mathrm{CO}}+n_{\mathrm{CO}_{2}}+n_{\mathrm{H}_{2} \mathrm{O}}-w-2 m-y
$$

where $f_{1}, f_{2}$ and $f_{3}$ are functions resulting from the balancing of number of moles from the global gasification reaction.

The values of $x, y$ and $z$ are obtained by equating the ratio of elemental atomic weight present in the biomass ( $C, H, O$ and $N$ ) to total weight of biomass and equate to the percentage elemental content obtained in proximate analysis for specific biomass. The molar concentration of water in the biomass, a, can be obtained by equating the percentage weight of moisture obtained from the proximate analysis to the ratio of weight of moisture in the biomass and the weight of biomass. The mole concentration of air required for stoichiometric, $m_{1}$ can be obtained by performing mole balance of the stoichiometric reaction.

More two equations need be established in order to obtain values of $n_{\mathrm{CO}}, n_{\mathrm{CO}_{2}}, n_{\mathrm{H}_{2}}, n_{\mathrm{H}_{2} \mathrm{O}}$ and $n_{\mathrm{CH}_{4}}$. These are obtained from the equilibrium constant of reaction occurring in the gasification zone, their reaction kinetics, and thermal balance which are methanation $\mathrm{R}_{4}\left(\mathrm{C}+2 \mathrm{H}_{2} \leftrightarrow \mathrm{CH}_{4}\right)$ and water-gas shift reaction $\mathrm{R}_{5}(\mathrm{CO}+$ $\mathrm{H}_{2} \mathrm{O} \leftrightarrow \mathrm{CO}_{2}+\mathrm{H}_{2}$ ). By assuming the thermodynamic equilibrium for all chemical reactions of ideal gases at 1 atm, the equilibrium constants for reactions $\mathrm{R}_{4}$ (Methanation) and $\mathrm{R}_{5}$ (Water-gas shift) respectively are:

$$
K_{1}=\frac{\left(n C H_{4}\right)\left(n_{\text {total }}\right)}{\left(n H_{2}\right)^{2}}
$$




$$
K_{2}=\frac{\left(n \mathrm{CO}_{2}\right)\left(n \mathrm{H}_{2}\right)}{(n \mathrm{CO})\left(\mathrm{nH}_{2} \mathrm{O}\right)}
$$

where $n_{\text {total }}$ is the total mole of producer gas, $K_{1}$ and $K_{2}$ are the equilibrium constants of methanation and water-gas shift reactions respectively resulting from the ratio of products to reactants of these reactions. The above equations reduce into:

$$
\begin{gathered}
f_{4}=0=K_{1}\left(n H_{2}\right)^{2}-\left(n \mathrm{CH}_{4}\right)\left(n_{\text {total }}\right) \\
f_{5}=0=K_{2}(n \mathrm{CO})\left(n \mathrm{H}_{2} \mathrm{O}\right)-\left(n \mathrm{CO}_{2}\right)\left(n \mathrm{H}_{2}\right)
\end{gathered}
$$

For equilibrium state of ideal gas mixture

$$
\ln K=-\frac{\Delta G_{T}^{O}}{R_{o} T}
$$

where $R_{o}$ is the universal gas constant, $8.314 \mathrm{~kJ} / \mathrm{kmolK}, \Delta G_{T}^{o}$ is the standard Gibbs function of reaction $T$ is the gasification temperature.

\subsection{Quantification of Irreversibilities}

Methods adopted equations derived in the designed thermochemical equilibrium model to predict irreversibility values which requires the application of ultimate and proximate analyses of biomass materials together with exergy analyses. These analyses could contribute a significant achievement that can be applied to the gasification process to find the quantity and quality of the syngas produced. Operations of this gasifier (downdraft gasifier) which applies a high temperature air gasification (HTAG) technology using a highly preheated air gasifying media to improve gas yield and quality is applied. The model formulation application is based on determination of process irreversibilities depending upon the change in various operating parameters. The effect of temperature and equivalence ratio shall be studied through the equilibrium model, which serves as the improvement tool in the field of gasifier design.

It should be noted that, effect of one parameter alone cannot give an adequate solution to conclude the results, hence varying model operating parameters would allow to predict optimal gasifier design parameters. It should also be observed that the central part of the biomass gasification process is the gasifier since it is one of the least efficient unit operations in the whole biomass to energy technology chain [14]. In this work the high temperature gasifier unit for analysis of the exergy balance of the biomass gasification process is that exergy values of all streams entering must be conserved by the total sum of the exergy values leaving the process and the process irreversibilities, expressed by “ 15 ”;

$$
\sum_{I N} \varepsilon_{j}=\sum_{\text {OUT }} \varepsilon_{k}+I
$$

where $\sum \varepsilon_{j}$ and $\sum \varepsilon_{k}$ are the exergy flow of all entering and leaving material streams respectively and $I$ is the irreversißBility and thbT degree of irreversibilities I is given by:

$$
\frac{I}{\varepsilon_{\text {in }}}=\frac{\varepsilon_{\text {in }}-\varepsilon_{\text {out }}}{\varepsilon_{\text {in }}}=1-\frac{\varepsilon_{\text {out }}}{\varepsilon_{\text {in }}}
$$

The total exergy of the streams (output) is dependent upon its chemical and physical composition and is given by " 17 ":

$$
\varepsilon_{c h, g a s}+\varepsilon_{\text {ph,gas }}
$$

The biomass and gasifying agent exergy (input) are respectively, $\varepsilon_{\mathrm{ch}, \text { biomass }}$ and $\varepsilon_{\mathrm{ph}, \mathrm{med}}$ : and therefore;

$$
I=\left(100-\frac{\varepsilon_{c h, g a s}+\varepsilon_{p h, g a s}}{\varepsilon_{c h, \text { biomass }}+\varepsilon_{\text {ph,med }}}\right) \%
$$

The Matlab equation solver program and Maple programs were used to calculate the formulated model equations to obtain the gaseous concentrations and irreversibility values. 


\section{Results and Discussions}

\subsection{Model Validation}

Table 1 shows the comparison between the results of gaseous compositions available from literature and predicted values using this model relations. The [15] model presented results using an equilibrium model in a downdraft gasifier with wood material of $20 \%$ moisture content at a temperature of $1073 \mathrm{~K}$ and equivalence ratio of 0.4 with a feedstock ultimate analysis of carbon $50 \%$, hydrogen $6 \%$, oxygen $44 \%$. The model assumes that all reactions are in thermodynamic equilibrium and that the pyrolysis products burns and achieve equilibrium in reduction zone before leaving the gasifier. The predicted results are in good agreement with the literature results for $\mathrm{CO}$ and $\mathrm{H}_{2}$ which in most cases are slightly higher. Model results for $\mathrm{CO}_{2}$ are desirable because are lower than those presented from the literature.

\subsection{The Proximate and Ultimate Analysis}

Results Based on Proximate Analysis: Table 2 shows the results based on proximate analysis related to the five biomass samples being studied. These results show; that rice husks have an ash content of $26.2 \%$. The moisture contents for the biomass materials was found to be less than $15 \%$, while the fixed carbon values for the sample was less than $20 \%$ and the value of volatile matter was $59.20 \%$.

Results Based on Ultimate Analysis: To change the default, adjust the template as follows. The same biomass materials were investigated employing the ultimate analysis, and the results of their characteristic properties. The results shown in Table 3 reveal that the biomass material, $C$ contents was less than $40 \%$ and $O$ content was less that $35 \%$ while the $H$ content was in the range of $4 \%$. The percentage content of sulphur and chlorine are neglected in the current study. Carbon content presence and ash content exhibits a role in determining the energy content. The experimental heating values for the presented biomass materials shows that Rice husks carbon contents was $35.6 \%$ and higher value of ash content $26.2 \%$ with heating value of $13,041 \mathrm{~kJ} / \mathrm{kg}$.

\subsection{Syngas Production}

In this paper, gasification model runs were performed by varying the temperature between $800 \mathrm{~K}$ and $1400 \mathrm{~K}$ and keeping the air equivalence ratio constant at $0.3,0.35,0.4$. Gas composition from rice husks and bagasse is shown

Table 1. Comparison of gaseous composition-current predicted values with [21] values.

\begin{tabular}{cccc}
\hline \multirow{2}{*}{ Syngas } & \multicolumn{3}{c}{ Syngas composition (\%) } \\
\cline { 2 - 4 } & Current Model & Reference data & \% Deviation \\
\hline $\mathrm{CO}$ & 18.4 & 19.6 & 6.1 \\
$\mathrm{CO}_{2}$ & 9.9 & 12 & 17.5 \\
$\mathrm{CH}_{4}$ & 0.13 & 0.6 & 78.3 \\
$\mathrm{H}_{2}$ & 17 & 21 & 19.0 \\
\hline
\end{tabular}

Table 2. Characteristic properties for the Rice husks derived by proximate analysis.

\begin{tabular}{ccccccc}
\hline \multirow{2}{*}{ Biomass type } & \multicolumn{3}{c}{ Proximate analysis (\%), dry basis } & & \multicolumn{2}{c}{$\begin{array}{c}\text { Heating values (kJ/kg) } \\
\text { (Experimental) }\end{array}$} \\
\cline { 2 - 8 } & Moisture & Volatile matter & Fixed carbon & Ash & HHV & LHV \\
\hline Rice Husks & 8.80 & 59.20 & 14.60 & 26.20 & 13,240 & 13,041 \\
\hline
\end{tabular}

Table 3. Biomass composition values for rice husks derived by ultimate analysis.

\begin{tabular}{ccccccc}
\hline \multirow{2}{*}{ Biomass type } & \multicolumn{3}{c}{ Elemental Composition (\%) } & \multicolumn{3}{c}{ Composition ratio } \\
\cline { 2 - 7 } & $\boldsymbol{C}$ & $\boldsymbol{H}$ & $\boldsymbol{O}$ & $\boldsymbol{N}$ & $\boldsymbol{H} / \boldsymbol{C}$ & $\boldsymbol{O} / \boldsymbol{C}$ \\
\hline Rice Husks & 35.60 & 4.50 & 33.40 & 0.19 & 0.1264 & 0.938 \\
\hline
\end{tabular}


in Figures 1-3. The production of $\mathrm{H}_{2}$ increased from $9.9 \%$ to $18.9 \%$ and the formation of $\mathrm{CO}_{2}$ ranges from $7.2 \%$ to $12.3 \%$. While this is the case for and $\mathrm{CO}_{2}$, $\mathrm{CO}$ production is reduced from $21.8 \%$ to $17.2 \%$. Generally, it can be observed that $\mathrm{H}_{2}$ composition increases as the gasification temperature is increased due to the effect of exothermal character of water-gas shift reaction $\left(\mathrm{CO}+\mathrm{H}_{2} \mathrm{O} \rightarrow \mathrm{CO}_{2}+\mathrm{H}_{2}\right)$ predominating around $1000 \mathrm{~K}$ and the water-gas reaction $\left(\mathrm{C}+\mathrm{H}_{2} \mathrm{O} \rightarrow \mathrm{CO}+\mathrm{H}_{2}\right)$ predominating at temperature of about $1300 \mathrm{~K}$. Water vapour, $\mathrm{H}_{2} \mathrm{O}$ and $\mathrm{CO}$ promotes $\mathrm{H}_{2}$ production in biomass gasification process via the water-gas shift reaction and water-gas reaction. The $\mathrm{CH}_{4}$ concentration is reduced for both biomass materials as the temperature is increased. This is because the $\mathrm{H}_{2}$ production reactions are endothermic and content of $\mathrm{CH}_{4}$ decrease because the endothermicity in the reactions favours the steam methane reforming reaction/methane decomposition reaction $\left(\mathrm{CH}_{4}+\mathrm{H}_{2} \mathrm{O} \rightarrow \mathrm{CO}+3 \mathrm{H}_{2}\right)$. The $\mathrm{CO}_{2}$ production is noted to increase for both biomass materials) as the temperature is increased in the current work. While this is the case for $\mathrm{CO}_{2}$, $\mathrm{CO}$ concentration is reduced for both biomass materials. This trend in the gas composition of the produced gas from the biomass materials in this study indicate the significance of the Bourdouard reaction ( $\mathrm{C}+\mathrm{CO}_{2} \leftrightarrow 2 \mathrm{CO}$ ) hence, a reduction in the $\mathrm{CO}$ concentration. The decrease in $\mathrm{CO}$ means a bourdouard reaction shift to the left side, hence increase production of $\mathrm{CO}_{2}$. This concludes that the reduction in CO production is because Boudouard reaction predominates at lower temperature than $900 \mathrm{~K}$. These results compare well with those presented by [16].

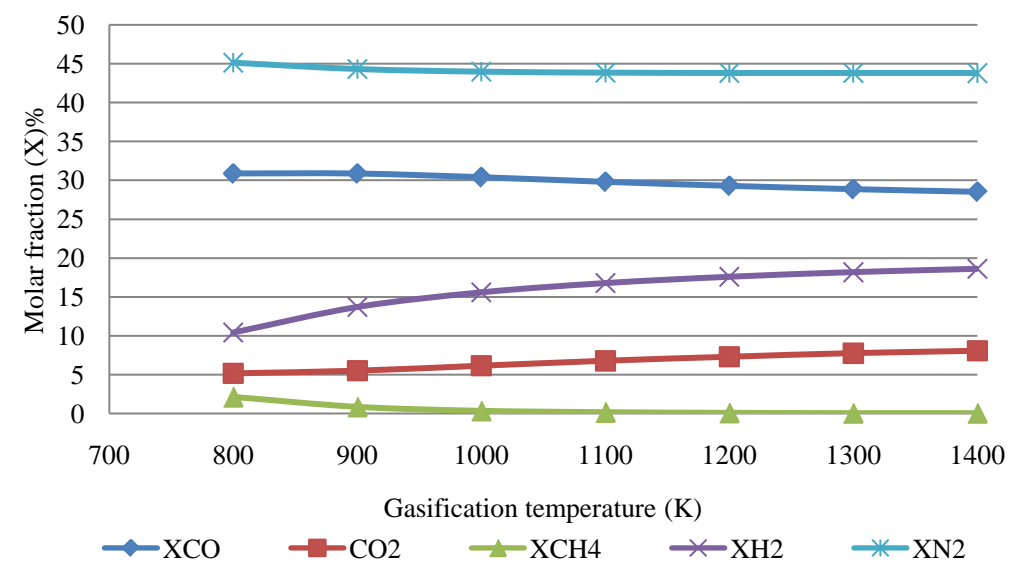

Figure 1. Effect of temperature on molar composition for $\mathrm{CO}, \mathrm{CH}_{4}, \mathrm{CO}_{2}$ and $\mathrm{H}_{2}$ gases from the rice husks type at an equivalent ratio of 0.3 .

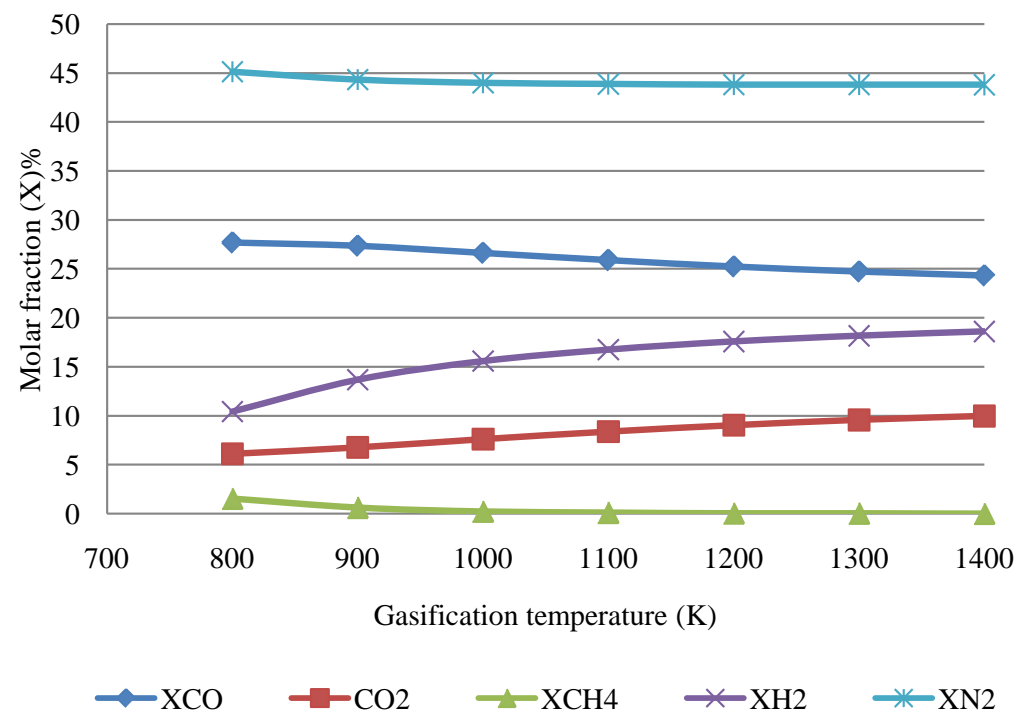

Figure 2. Effect of temperature on molar composition for $\mathrm{CO}, \mathrm{CH}_{4}, \mathrm{CO}_{2}$ and $\mathrm{H}_{2}$ gases from the rice husks type at an equivalent ratio of 0.35 . 


\subsection{Evaluation of Losses}

The effect of gasification temperatures of $800 \mathrm{~K}$ and $1400 \mathrm{~K}$ on exergy efficiency at constant equivalence ratios of 0.3, 0.35 and 0.4 are presented in Figure 4. The results show that high temperatures and equivalent ratio increase favoured the reduction of losses. A reduction is observed at about the temperature range between $800 \mathrm{~K}$ and $140 \mathrm{~K}$ with an equivalence ratio of 0.3 . This means that the irreversibilities of about $19.1 \%$ to $18.6 \%$ are encountered in this range. For an equivalence ratio of 0.35 , second law efficiency based chemical exergy values increase from $84.2 \%$ to $84.6 \%$ at temperature range between $800 \mathrm{~K}$ and $1400 \mathrm{~K}$ with irreversibility values of $15.8 \%$ to $15.4 \%$. While for an equivalence ratio of 0.4 , losses reduces from $14.5 \%$ to $6.7 \%$ temperature range between $800 \mathrm{~K}$ and $1400 \mathrm{~K}$. While for an equivalence ratio of 0.35 and 0.3 , losses reduces from of $20.4 \%$ to $10.9 \%$ and $26.2 \%$ and $16.4 \%$ respectively. Irreversibility values reduces as the equivalent ratio increases and were less than $27 \%$.

\section{Conclusion}

Gasification of biomass materials especially the second generation biofuels such as agricultural residues and industrial wastes from biomass is a significant technology for energy production. The most obvious beneficiary will be the developing countries such as Tanzania whose economies are often tied to agricultural produce in which the wastes are abundant and are lacking convention processes. It is therefore believed that in the developed process by varying gasification temperature and equivalence ratio, the efficiency values obtained indicate that the energy production process is feasible since these results give an indication on the reduction of the degree of irreversibility values. The irreversibility values (I) resulted under this study were less than $27 \%$. Also, by the

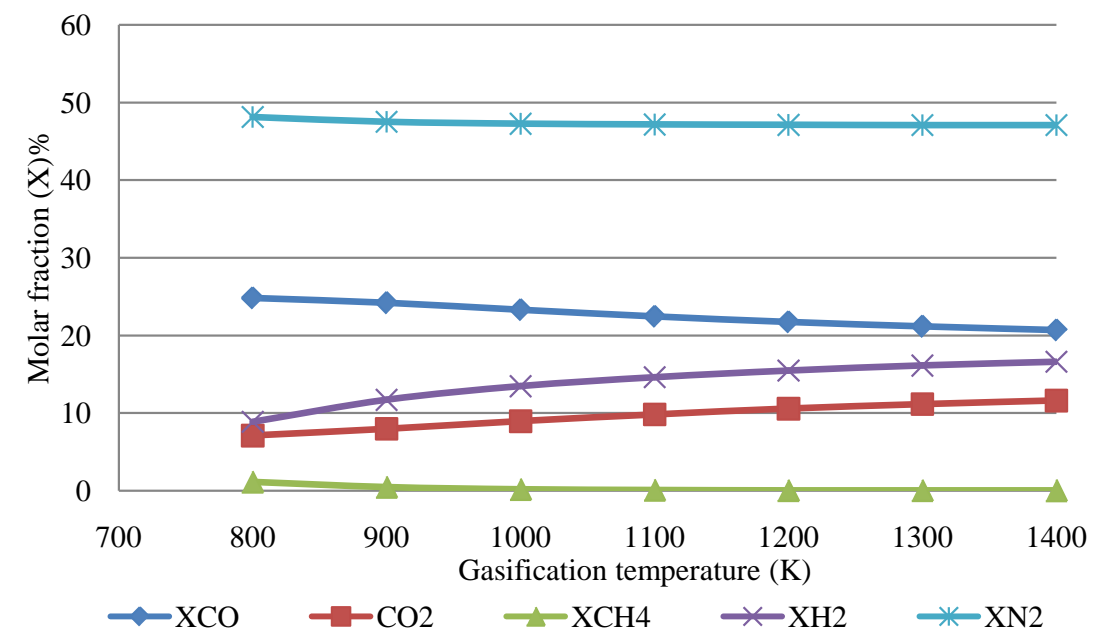

Figure 3. Effect of temperature on molar composition for $\mathrm{CO}, \mathrm{CH}_{4}, \mathrm{CO}_{2}$ and $\mathrm{H}_{2}$ gases from the rice husks type at an equivalent ratio of 0.4 .

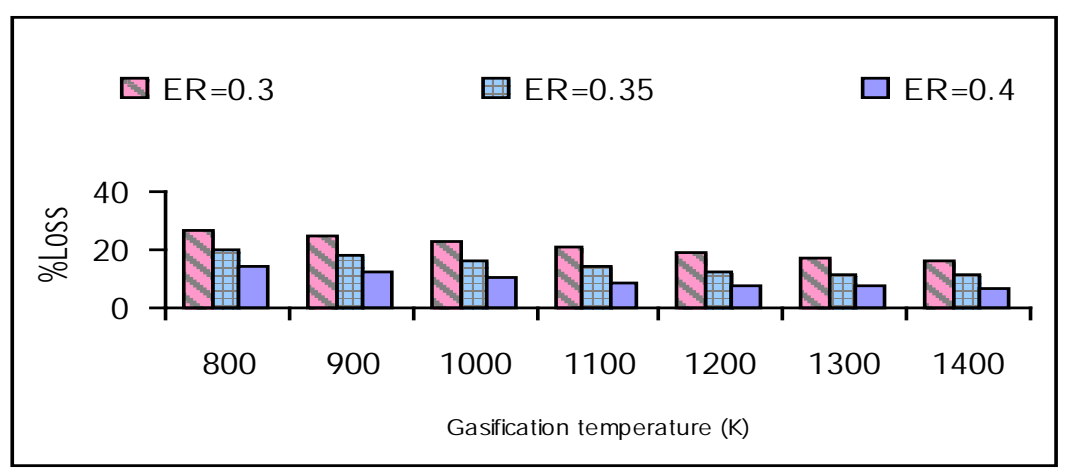

Figure 4. Effect of temperature on exergy efficiencies at equivalence ratios of 0.3, 035 and 0.4 . 
enhancement system efficiency, biomass resources can be protracted to be used in energy generation. Hence, gasification process outputs are biomass resource dependant.

\section{References}

[1] Wilson, L., Yang, W., Blasiak, W., John, G. and Mhilu, C. (2007) Opportunities and Challenges of Biomass Energy for Heat and Power Production in Tanzania. 3rd International Green Energy Conference, Västerås, Sweden.

[2] Rösch, C. and Wintzer, D. (1997) Gasification and Pyrolysis of Biomass. TAB Report No. 049, Berlin, p. 116.

[3] Gautam, G. (2010) Parametric Study of a Commercial-Scale Biomass Downdraft Gasifier: Experiments and Equilibrium Modeling. Thesis of Graduate Faculty of Auburn University, Albama.

[4] Mambre, V., Imberty, M. and Guerquin, M. (2008) Biomass Gasification for Production of Green Energy (Combined Heat and Power, Green Methane). In: International Gas Union Research Conference, IGRC, Paris.

[5] Peterson, D. and Haase, S. (2009) Market Assessment of Biomass Gasification and Combustion Technology for Smalland Medium-Scale Applications. Technical Report NREL/TP-7A2-46190.

[6] Ponzio, A., Kalisz, S. and Blasiak, W. (2006) Effect of Operating Conditions on Tar and Gas Composition in High Temperature Air/Steam Gasification (HTAG) of Plastic Containing Waste. Journal of Fuel Processing Technology, 87, 223-233. http://dx.doi.org/10.1016/j.fuproc.2005.08.002

[7] Ganapathy, T., Alagumurthi, N., Gakkhar, R. and Murugesan, K. (2009) Exergy Analysis of Operating Lignite Fired Thermal Power Plant. Journal of Engineering Science and Technology Review, 2, 123-130.

[8] Cao, J., Yang, X., Wang, J. and Yu, S. (2005) The High Temperature Gas-Cooled Reactor (HTGR) coupled with Gas Turbine (GT). 18th International Conference on Structural Mechanics in Reactor Technology (SMiRT 18) Beijing, China.

[9] Taufiq, B., Masjuki, H., Mahlia, T., Amalina, M., Faizul, M. and Saidur, R. (2007) Exergy Analysis of Evaporative Cooling for Reducing Energy Use in a Malaysian Building. Journal of Desalination, 209, 238-243. http://dx.doi.org/10.1016/j.desal.2007.04.033

[10] Szargut, J. (2005) Exergy Analysis, Improving Thermal Processes. Journal of Research in Progress Thermodynamics, 7.

[11] Moran, M. (1989) Availability Analysis (Corrected Ed.). ASME Press, New York.

[12] Szargut, J., Morris, D. and Steward, F. (1988) Exergy Analysis of Thermal, Chemical, and Metallurgical Processes. Hemisphere, New York.

[13] Parikh, J., Channiwala, S. and Ghosal, G. (2007) A Correlation for Calculating Elemental Composition from Proximate Analysis of Biomass Materials. Journal of Fuel, 86, 1710-1719. http://dx.doi.org/10.1016/j.fuel.2006.12.029

[14] Ptasinski, K., Hamelinck, C. and Kerkhof, P. (2002) Exergy Analysis of Methanol from the Sewage Sludge Process. Journal of Energy Conversion Management, 43, 1445-1457. http://dx.doi.org/10.1016/S0196-8904(02)00027-4

[15] Zainal, A., Ali, R., Lean, C. and Seetharamu, K. (2001) Prediction of the Performance of a Downdraft Gasifier Using Equilibrium Modeling for Different Biomass Materials. Journal of Energy Conversion Management, 42, 1499-1515. http://dx.doi.org/10.1016/S0196-8904(00)00078-9

[16] Boateng, A., Walawender, W., Fan, L. and Chee, C. (1992) Fluidized-Bed Steam Gasification of Rice Hull, Bioresource Technology. Bioresource Technology, 40, 235-239. Parikh, J., Channiwala, S. and Ghosal, G (2007) A Correlation for Calculating Elemental Composition from Proximate Analysis of Biomass Materials. Journal of Fuel, 86, 1710-1719. 